\title{
Interrelationship between Cerebrovascular Disease and Periodontitis
}

\author{
${ }^{1}$ Kamontip Chaikomon, ${ }^{2}$ Pimpimol Yooprasert, ${ }^{3}$ Kasemsuk Yothasamutr, ${ }^{4}$ Monchai Siribamrungwong
}

\begin{abstract}
Cerebrovascular disease (CVD) is the second most common cause of death and contributes to a high morbidity worldwide. The major etiology is an atherosclerosis. Many well-known risk factors, such as hypertension, dyslipidemia and diabetes, are defined as traditional risk factors. Treatment and control of traditional risk factors also improve both cardiovascular and cerebrovascular outcomes. To date, many studies reported an association between stroke and nontraditional risk factors, such as infectious diseases or inflammatory process. Periodontal disease (PD) is an infection of the gum and other toothsupporting structures, with an on going inflammatory process and affects a large number of populations worldwide. Current evidence demonstrated the local and systemic inflammatory effects in periodontitis induced an atherosclerosis. This review aims to provide the current knowledge on the association between periodontal disease and cerebrovascular disease.
\end{abstract}

Keywords: Cerebrovascular disease, Periodontitis, Atherosclerosis, Endothelial dysfunction, Inflammation.

How to cite this article: Chaikomon $\mathrm{K}$, Yooprasert $\mathrm{P}$, Yothasamutr K, Siribamrungwong M. Interrelationship between Cerebrovascular Disease and Periodontitis. Int J Experiment Dent Sci 2015;4(1):47-52.

Source of support: Nil

Conflict of interest: None

\section{INTRODUCTION}

Cerebrovascular disease (CVD) affects a large number of the population and contributes to a high morbidity and mortality worldwide. Multiple associated risk factors have been reported, and are well-known as 'traditional risk factors', such as hypertension, diabetes mellitus, hyperlipidemia, cigarette smoking and cardiovascular disease. However, a significant number of patients possess none of the mentioned factors, thereby raising an attempt to identify other independent risk factors. Many published studies reported that some infectious diseases

\footnotetext{
1-4Physician

${ }^{1-4}$ Department of Medicine, Lerdsin General Hospital, College of Medicine, Rangsit University, Bangkok, Thailand
}

Corresponding Author: Monchai Siribamrungwong Physician, Department of Medicine, Lerdsin General Hospital College of Medicine, Rangsit University, Bangkok, Thailand Phone: 6623539800, e-mail: monsiri_dr@hotmail.com and inflammatory process were related to a higher rate of cerebrovascular disease. Periodontal disease is a common infectious disease in the global population; it is caused by bacterial infection and resulted in an activation of the host's inflammatory response. ${ }^{1}$ The ongoing inflammatory process is believed to increase the risk of cerebrovascular disease, as it has been proposed in many other systemic inflammatory diseases. ${ }^{2-4}$ This review aims to provide the current knowledge on the association between periodontal disease and cerebrovascular disease.

\section{CEREBROVASCULAR DISEASE}

Cerebrovascular disease is commonly referred to as stroke. The World Health Organization (WHO) defines stroke as rapidly developing clinical signs of focal (or global) disturbances of cerebral function, with symptoms lasting 24 hours or longer or leading to death with no apparent cause other than of vascular origin. Patients with tumors, poisoning or trauma are excluded. ${ }^{5}$ Generally, stroke is divided into two categories: ischemia and hemorrhage. Ischemic stroke is a brain damage resulted from a reduction in cerebral blood supply due to an obstruction of blood vessels, ${ }^{6}$ whereas hemorrhagic stroke is caused by intracerebral bleeding. ${ }^{5}$ In addition, a brief episode of neurological dysfunction lasting less than 24 hours resulting from cerebral ischemia and not associated with permanent cerebral infarction is defined as transient ischemic attack (TIA). ${ }^{7}$

The 1990 Global Burden of Disease reported that CVD is the second most common cause of death worldwide. ${ }^{5}$ According to the WHO report in 2002, 15 million people suffered from stroke, 5 million died, and another 5 million were permanently disabled. In the United States, approximately 7,95,000 patients are affected each year. In the Caucasian population, approximately $80 \%$ of cases are ischemic stroke. ${ }^{5}$ Majority of it is due to an atherosclerosis, ${ }^{8}$ either in the intracranial or extracranial arterial system.

\section{PATHOPHYSIOLOGY OF ATHEROSCLEROSIS}

Atherosclerosis is a development of fatty streak in the vascular wall, which is believed to begin since the childhood period. ${ }^{9}$ It gradually progresses with increasing age, so that it is perceived as another chronic inflammatory disease. $^{10}$ 
Endothelial dysfunction is an initial step in atherogenesis, resulted from inhibition of nitric oxide (NO) production by oxidized low-density lipoprotein (LDL)induced caveolin-1 pathway. ${ }^{11}$ Nitric oxide is an endothelium-derived vasodilator and plays a role in preventing LDL oxidization. With a decreased NO level, oxidized LDL increases and vasoconstriction occurs, causing progressive endothelial dysfunction. In addition, hypercholesterolemia also predisposes endothelial dysfunction ${ }^{12}$ as studies have shown that statin (cholesterol-lowering drug) administration could improve endothelial dysfunction by increasing NO production via increasing activity of endothelial nitric oxide synthase (eNOS). ${ }^{13}$

Injured endothelial cells express intracellular adhesion molecule-1 (ICAM-1), vascular cell adhesion molecule-1 (VCAM-1) and endothelial leukocyte adhesion molecule-1 (ELAM-1). Monocytes and T-lymphocytes adhere to these receptors, and migrate into the intimal layer. ${ }^{14}$ Once the inflammatory process is triggered, the macrophage scavenger receptors for modified lipoproteins (e.g. oxidized LDL) are activated under an influence of macrophage colony-stimulating factor, stimulate macrophages transformation into foam cells. ${ }^{15}$ Foam cells accumulation is characteristic of atherosclerosis as it is a major component in the lipid core of atheromatous plaque. ${ }^{16}$ Intracellular and extracellular lipids, together with lipoproteins (LDL, HDL, VLDL remnant and apolipoprotein E) bind with biglycan found in the intima. ${ }^{17}$ Later, smooth muscle cells (which migrate into the area) and extracellular matrix accumulation causes focal thickening of the intimal layer. ${ }^{18}$ Collagen secreted from smooth muscle cells forms the fibrous cap, simultaneously with accumulation of macrophages, foam cells and T-lymphocytes in the atheroma core. ${ }^{19,20}$ Eventually, fatty streaks turn into atheromatous plaque, covered with a fibrous cap with its core containing lipid, cells and vasa vasorum that provide the blood supply. ${ }^{21}$

Macrophages can be activated by oxidized LDL, stress proteins, bacterial endotoxin or apoptotic cells. The activated macrophages secrete various chemokines and act as antigen-presenting cells for activating T-lymphocytes. ${ }^{14}$ Activated T-lymphocytes release inflammatory cytokines, such as tumor necrosis factor (TNF) $\beta$ and $\gamma$-interferon that can stimulate macrophages activation, endothelial cells and smooth muscle cells proliferation. ${ }^{15} \gamma$-interferon decreases collagen synthesis, and together with matrix metalloproteinases (MMPs), released from the activated macrophage, reduced the strength of a fibrous cap. This process leads to atherosclerotic plaque rupture, causing thrombotic complication of atherosclerosis. ${ }^{22}$

C-reactive protein (CRP) is an acute phase reactant synthesized primarily by the liver, under the influence of interleukin (IL)-6 in response to an inflammatory process. ${ }^{22,23}$ Therefore, it is elevated in any conditions associated with increased inflammatory response. Cerebrovascular disease is believed to play a role in atherogenesis, ${ }^{24}$ as supported by a large number of studies that demonstrated a correlation between a high level of CRP and atherosclerotic events. Cerebrovascular disease is now widely accepted as a prognostic factor for cardiovascular events and CVD. ${ }^{25,26}$

\section{PERIODONTAL DISEASE}

Periodontal disease (PD) is an infection of the gum and other tooth-supporting structures. Aggregatibacter actinomycetemcomitans and Porphyromonas gingivalis are common causative organisms. ${ }^{1}$ The course of disease is usually slow and progressive, with the ongoing inflammatory process that leads to connective tissue and bone damage. It is a common infectious disease worldwide with an estimated prevalence of $47.2 \%$ in adult aged 30 years and older. ${ }^{27}$ However, the prevalence is higher in some groups of population, especially those with diabetes mellitus and those with tobacco use. Thus, it is believed that PD and systemic diseases share the same common risk factors, such as cigarette smoking, excessive alcohol consumption, improper diet, stress and poor hygiene. ${ }^{1,28}$

Patients with PD are often asymptomatic but, in advanced cases, patients may present with non-specific signs and symptoms, such as gum swelling or bleeding, and tooth insecurity or tooth loss. The clinical diagnosis requires evaluation by trained examiner which often demonstrated evidence of gingival inflammation, loss of connective tissue surrounding the teeth (measured by probe assessment) and radiography may show bone loss in severe cases. ${ }^{29}$

Presence of bacterial antigen triggers host immunity, activating the inflammatory cascade. Lipopolysaccharides (in Gram-negative bacilli) are powerful stimulant that cause host cells (neutrophils, T-lymphocytes and macrophages) to release chemical mediators, such as cytokines, chemokines and CRP. The released MMPs activate TNF- $\alpha$, IL- 1 and IL- 6 activity, and enhance the collagen breakdown process. TNF- $\alpha$, IL-1 and IL- 6 stimulate osteoclast activity resulting in bone resorption, and TNF- $\alpha$ also inhibits collagen production. The severity of $\mathrm{PD}$, as in other chronic inflammatory diseases, depends on the balance between the host's destructive and protective mechanism. ${ }^{1}$

Treatment of PD mainly consists of bacteria removal and minimizing the risk factors (for prevention of recurrence). Antibiotics can be used either in local or systemic form. Local treatment with doxycycline results in an improved clinical attachment level (a parameter 
measured by clinical examiner). ${ }^{1}$ Doxycycline, apart from its antimicrobial activity that alters the bacterial microenvironment, reduces the inflammatory response by inhibiting MMPs activity. Indications for systemic antibiotic administration include aggressive periodontitis (usually caused by A. actinomycetemcomitans), recurrent or refractory disease, or in immunocompromised host. Example of this is the use of metronidazole for acute ulcerative gingivitis.

\section{PERIODONTAL DISEASE AND CEREBROVASCULAR DISEASE}

As previously mentioned, the main cause of stroke (especially in ischemic stroke) is atherosclerosis, thus any inflammation and infection that promote atherosclerosis might be considered as a stroke risk factor. Many recent studies have reported a positive association between PD and incidence of CVD as well as with other systemic diseases, e.g. diabetes mellitus, cardiovascular disease and osteoporosis. ${ }^{2-4}$

Grau et al conducted a case-control study in 303 patients after acute ischemic stroke or TIA. All subjects underwent a complete clinical and radiographic dental examination. They found that severe periodontitis in younger male patients ( $<60$ years) is an independent risk factor for ischemic stroke. ${ }^{30}$ The study of 41,380 health professionals by Joshipura et al found that a baseline of fewer teeth ( $\leq 24$ teeth) and a history of periodontal disease were associated with an increased risk of ischemic stroke. ${ }^{31}$ Data from the National Health and Nutrition Examination Survey (NHANES) I analysis also showed that PD is a risk factor for nonhemorrhagic stroke $\mathrm{e}^{32}$ and the NHANES III data analysis reported an association between cumulative PD that were based on median percentage of clinical attachment loss and a history of stroke. ${ }^{33}$

In this article, we summarized the proposed pathogenesis for atherosclerosis development following PD, the main mechanism responsible for its association with an increased CVD prevalence.

\section{Periodontal Disease and Inflammatory Process}

Periodontal infection stimulates both local and systemic inflammatory responses. Initially, periodontal pathogens infect the gum and trigger local immune responses. With progression from gingivitis to periodontitis, tooth-surrounding connective tissue is also inflamed. This enables bacteria and local inflammatory mediators to enter the bloodstream, activating systemic inflammatory process.

An inflammation caused by periodontal disease is associated with TNF- $\alpha$, IL-1, IL-6, CRP, adhesion molecules and MMPs secretion, ${ }^{1,34,35}$ these repeatedly activate an inflammatory response. Moreover, IL-1, IL-6 and TNF- $\alpha^{36}$ cause further endothelial dysfunction, leading to atherosclerosis associated with atheroma plaque rupture. $^{22}$

\section{Immune-mediated Mechanism}

Heat shock proteins (HSPs) are intracellular proteins that act as chaperones in preventing apoptosis under stress condition. ${ }^{37}$ Various types of HSP (e.g. HSP47, HSP60, HSP70) ${ }^{38}$ have been found in many cells, including endothelial cells, smooth muscle cells and mononuclear cells. With inflammation, HSP migrates from the intracellular compartment to the cell membrane for expression.

In periodontal disease, the cross-reactivity between bacterial HSP and host's HSP60 on endothelial cell was reported. This means that antibody targeted at bacterial HSP also bind with endothelial HSP60, resulting in endothelial damage. This process later allows the host immune response to generate anti-HSP60 antibodies (since the immune system recognized HSP60 as a foreign antigen) known as autoantibody formation. Endothelial cells will be damaged by anti-HSP60 antibodies, ${ }^{39}$ leading to progression of atherosclerosis. ${ }^{40}$

\section{The Direct Link of Periodontal Pathogens and Atherosclerosis}

Recently, many studies have reported a successful bacterial DNA extraction from atheromatous plaque obtained from various vascular sites. It implies that periodontal pathogens had lodged not only in oral cavity but in the arterial system also. Fiquero et al detected the DNA of periodontal pathogen in atheromatous plaques from carotid artery endarterectomy using nested polymerase reaction method. The three most common bacterial species were P. gingivalis, A actinomycetemcomitans and Tannerella forsythia. ${ }^{41}$ Another study showed that Prevotella intermedia could also be found in carotid atherosclerotic plaques and may associate with nonhemorrhagic stroke. ${ }^{42}$ One case-control study suggested that IgA antibody level for A. actinomycetemcomitans might predict an occurrence of stroke, while IgA level for $P$. gingivalis may predict a recurrence of stroke. ${ }^{43}$

Another study proved that $P$. gingivalis invaded and infected endothelial cells by demonstrating intracellular $P$. gingivalis fimbriae action (in mediating an adhesion between cells by activating the expression of ICAM-1, VCAM-1, E- and P-selectins), promoting leukocyteendothelial cell interaction. ${ }^{28}$ In addition, $P$. gingivalis fimbriae can induce inflammatory response cytokines, such as TNF- $\alpha$, IL-6 or IL-8, resulting in alveolar bone resorption. ${ }^{44}$ 


\section{Periodontal Disease and Endothelial Dysfunction}

Endothelial dysfunction occurs in the early stage of atherosclerosis, before clinical symptoms become apparent. Normal endothelial cells have a protective mechanism against inflammation, cellular proliferation and thrombosis, by the presence of endothelium-derived NO, which maintain vascular smooth muscle tone..$^{45}$ Inflammation exerts a procoagulant effect on endothelium and inhibits vasodilation. Many studies showed that infection by organisms, such as Helicobacter pylori, Chlamydia pneumoniae and cytomegalovirus can results in endothelial dysfunction ${ }^{46}$ as well as with other risk factors for atherosclerosis.

Hagashi et al studied forearm blood flow in response to acetylcholine and sodium nitroprusside in healthy and hypertensive subjects with and without periodontitis. The study showed that periodontal therapy was associated with acetylcholine-induced vasodilation in periodontitis patients (either with or without hypertension), and a reduction in CRP and IL-6 serum concentration. ${ }^{47}$ Amar et al measured flow-mediated dilation and nitroglycerinmediated dilation in the brachial artery in subjects with and without advanced periodontitis. Subjects with hypercholesterolemia, diabetes mellitus, hypertension and history of cigarette smoking were excluded. Subjects with advanced periodontitis had lower flow-mediated dilatation and higher level of serum hs-CRP, showing that advanced periodontitis correlates with endothelial dysfunction and systemic inflammation. ${ }^{48}$ Recently, many studies have reported that periodontal treatment resulted in an improvement of endothelial dysfunction. ${ }^{47,49}$

\section{PERIODONTAL TREATMENT AND CEREBROVASCULAR DISEASE}

Periodontal disease has been shown in many studies to correlate with CVD by enhancing atherosclerosis. However, since these two conditions share some common risk factors, it is hard to conclude that they are coexisting diseases of whether PD actually increases risk of CVD. Clinical trials have been conducted to determine if periodontal treatment can reduce stroke incidence.

Patients with PD usually have CRP level $>2.1 \mathrm{mg} / \mathrm{l}$. Many studies reported a reduction in CRP or highsensitivity CRP in PD patients who received periodontal therapy, and a meta-analysis concluded the weight mean different of reductions of CRP after therapy of $0.50 \mathrm{mg} / 1 .^{50}$ Other inflammatory chemokines (such as IL, TNF- $\alpha$, fibrinogen, MMPs) have also been studied. One study collected IL-1 $\beta$, MMP-8, IL-8 from gingival crevicular fluid in chronic periodontitis subjects ${ }^{51-53}$ and found that the level decreased after short-term surgical treatment, especially 4 weeks after scaling and root planning. ${ }^{54}$
Another study in patients with type 2 diabetes mellitus who had chronic periodontitis reported that nonsurgical periodontal treatment was associated with a reduction in levels of IL, TNF- $\alpha$ and fibrinogen. Moreover, a study showed that periodontal therapy helped to improve glycemic control. ${ }^{55}$

With studies reporting a reduction in arterial blood flow in patients with PD, Tonetti et al showed an improvement in flow-mediated dilatation of brachial artery and reduced plasma soluble E-selectin in PD patients who received intensive therapy. ${ }^{49}$ Another study also showed an improvement of endothelial dysfunction following PD treatment. ${ }^{47}$ A study that measured common carotid artery intima media thickness (CCA-IMT) demonstrated a regression in CCA-IMT progression with improvement in clinical or microbial periodontal status after treatment. The study was determined by probe examination and dominant bacteria from subgingival sample after adjusting for confounding factors (i.e. age, sex, smoking or diabetes mellitus). ${ }^{56}$

A case-control study by Lee et al categorized 510,762 patients with PD into three groups: dental prophylaxis, intensive PD treatment, or no treatment. Patients who received dental prophylaxis had the lowest incidence rate of ischemic stroke, while patients with no treatment had the highest. The stroke hazard ratio of dental prophylaxis and intensive treatment groups were lower than the no-treatment group. ${ }^{57}$ However, since there are only a small number of clinical trials that measured clinical CVD events, a systemic review cannot conclude that periodontal therapy can decrease cardiovascular disease burden, but it concluded that there were both improvement in systemic inflammation and endothelial dysfunction after receiving PD treatment. ${ }^{58}$

Hyperlipidemia is a traditional risk factor for cardiovascular disease and CVD. Many studies attempted to find the association between PD and hyperlipidemia, but only a few study are able to demonstrate a correlation between these two conditions, ${ }^{59,60}$ with some studies reported that periodontal treatment can decrease serum lipid level. ${ }^{61,62}$

\section{CONCLUSION}

Many studies demonstrate that PD correlates positively with CVD, and identify PD as an independent risk factor for stroke development. This correlation is best explained by an increased atherosclerosis. To date, only a few studies are able to report a decreased stroke incidence after receiving periodontal treatment and there is not enough evidence so a prospective randomized controlled trial with intervention should be conducted to provide 
further information for a standard recommendation for periodontal care to prevent stroke. The oral cavity is a portal of entry as well as the site of disease for microbial infections that affect general health. ${ }^{63}$

\section{REFERENCES}

1. Serio FG, Duucan TB. The pathogenesis and treatment of periodontal disease [internet]. 2009 [cited 2014 Jan 2]. Available at: http://www.ineedce.com/courses/1686/pdf/pathogenesisandtreatment.pdf.

2. Linden GJ, Lyons A, Scannapieco FA. Periodontal systemic associations: review of the evidence. J Periodontal 2013;84 (4 Suppl):8-19.

3. Kinane DF, Marshall GJ. Periodontal manifestations of systemic disease. Aust Dent J 2001;46(1):2-12.

4. Otomoto-Corgel J, Pucher JJ, Rethman MP, Reynold MA. State of the science: chronic periodontitis and systemic health. J Evid Based Dent Pract 2012;12(Suppl 3):20-28.

5. Joshipura K. The relationship between oral conditions and ischemic stroke and perivascular disease. Am Dent Assoc 2002;133(Suppl):23S-30S.

6. O'Neill D. Global burden of stroke: an underestimate. Lancet 2014;383(9924):1205.

7. Easton JD, Saver JL, Albers JW, Alberts MJ, Chaturvedi S, Feldmann E, et al. Definition and evaluation of transient ischemic attack. Stroke 2009;40(6):2276-2293.

8. Linsberg PJ, Grau AJ. Inflammation and infections as risk factors for ischemic stroke. Am Heart Assoc 2003;34(10): 2518-2534.

9. McGill HC Jr, McMahan CA, Herderick EE, Malcom GT, Traycy $\mathrm{RE}$, Strong JP, et al. Origin of atherosclerosis in childhood and adolescence. Am Soc Clin Nut 2000;72(Suppl):1307s-1315s.

10. Ross R. Atherosclerosis: an inflammatory disease. N Engl J Med 1999;340(2):115-126

11. Kinlay S, Libby P, Ganz P. Endothelial function and coronary artery disease. Curr Opin Lipidol 2001;12(4):383-389.

12. Tousoulis D, Kampoli AM, Tentolouris C, Papaqeorqiou N, Stefanadis $\mathrm{C}$. The role of nitric oxide on endothelial function. Curr Vasc Pharmacol 2012;10(1):4-18.

13. Davignon J, Ganz P. Role of endothelial dysfunction in atherosclerosis. Circulation 2004;109(Suppl III):III-27-III-32.

14. Hansson GK, Robertson AK, Söderberg-Nauclér C. Inflammation and atherosclerosis. Annu Rev Pathol 2006;1: 297-329.

15. Libby P, Ridker PM, Maseri A. Inflammation and atherosclerosis. Circulation 2002;105(9):1135-1143.

16. Dhadse P, Gattani D, Mishra R. The link between periodontal disease and cardiovascular disease: how far we have come in last two decades? J Ind Soc Periodont 2010;14(3):148-154.

17. O’Brien KD, Olin KL, Alpers CE, Chiu W, Ferguson M, Hudkins K, et al. Comparison of apolipoprotein and proteoglycan deposits in human coronary atherosclerotic plaques: colocalization of biglycan with apolipoproteins. Circulation 1998;98(6):519-527.

18. Davies MJ, Woolf N, Rowles PM, Pepper J. Morphology of the endothelium over atherosclerotic plaques in human coronary arteries. Br Heart J 1988;60(6):459.

19. Kockx MM, De Meyer GR, Muhring J, Jacob W, Bult H, Herman AG. Apoptosis and related proteins in different stages of human atherosclerotic plaques. Circulation 1998;97(23): 2307-2315.
20. Zhao XQ. Pathogenesis of atherosclerosis[Internet]. 2013 [cited 2014 Jan 2]. Available at: http://www.uptodate.com/contents/ pathogenesis-of-atherosclerosis.

21. Barger AC, Beeuwkes R 3rd, Lainey LL, Silverman KJ. Hypothesis: vasa vasorum and neovascularization of human coronary arteries - a possible role in the pathophysiology of atherosclerosis. N Engl J Med 1984;310(3):175.

22. Libby P. Mechanisms of acute coronary syndromes and their implications for therapy. N Engl J Med 2013;368(21):2004-2013.

23. Napali MD, Schwaninger M, Cappelli R, Ceccarelli E, Gianfilippo GD, Donati C, et al. Evaluation of C-reactive protein measurement for assessing the risk and prognosis in ischemic stroke: a statement for health care professionals from the CRP pooling project members. Stroke 2005;369(6): 1316-1329.

24. Singh SK, Suresh MV, Voleti B, Aglawal A. The connection between C-reactive protein and atherosclerosis. Ann Med 2008;40(2):110-120.

25. Ridker PM. C-reactive protein: a simple test to help predict risk of heart attack and stroke. Circulation 2003;108(12):e81-85.

26. Rost NS, Wolf PA, Kase CS, Kelly-Hayes M, Silbershatz H, Massaro JM, et al. Plasma concentration of C-reactive protein and risk of ischemic stroke and transient ischemic attack: the Framingham study. Stroke 2001;32(11):2575-2579.

27. Eke PI, Thornton-Evans G, Dye B, Genco R. Advances in surveillance of periodontitis: the centers for disease control and prevention periodontal disease surveillance project. J Periodontol 2012;83(11):1337-1342.

28. Lockhart PB, Bolger AF, Papapanou PN, Osinbowale O, Trevisan M, Levison ME, et al. Periodontal disease and atherosclerotiv vascular disease: does the evidence support an independent association?-a scientific statement from the American Heart Association. Circulation 2012;125(20):1-25.

29. Friedewald VE, Kornman KS, Beck JD, Genco R, Goldfine A, Libby $\mathrm{P}$, et al. The American journal of cardiology and journal of periodontology editors' consensus: periodontitis and atherosclerotic cardiovascular disease. Am J Cardiol 2009;104(1):59-68.

30. Grau AJ, Becher H, Ziegler CM, Lichy C, Buggle F, Kaiser C, et al. Periodontal disease as a risk factor for ischemic stroke. Stroke 2004;35(2):496-501.

31. Joshipura KJ, Hung HC, Rimm EB, Willett WC, Asherio A. Periodontal disease, tooth loss and incidence of ischemic stroke. Stroke 2003;34(1):47-52.

32. Wu T, Trevisan M, Genco RJ, Dorn JP, Falkner KL, Sempos CT. Periodontal disease and risk of cerebrovascular disease: the first national health and nutrition examination survey and its follow-up study. Arch Intern Med 2000;160(18):2749-2755.

33. Lee HJ, Garcia RI, Janket SJ, Jones JA, Mascarenhas AK, Scott $\mathrm{TE}$, et al. The association between cumulative periodontal disease and stroke history in older adults. J Periodontol 2006;77(10):1744-1754.

34. Loos BG, Craandijk J, HoekFj, Wertheim-van Dillen PM, van der Velden U. Elevation of systemic markers related to cardiovascular diseases in peripheral blood of periodontitis patients. J Periodontal 2000;71(10):1528-1534.

35. Loos BG. Systemic markers of inflammation in periodontitis. J Periodontal 2005;75(Suppl 11):2106-2015.

36. Esper RJ, Nordaby RA, Vilariño JO, Paragano A, Cacharrón JL, Machado RA. Endothelial dysfunction: a comprehensive appraisal. Cardiovasc Diabetol 2006;5:4. 
37. Li Z, Srivastava P. Heat-shock proteins. Curr Protoc Immunol 2004 Feb;Appendix 1:Appendix 1T.

38. Roma P, Catapano AL. Stress proteins and atherosclerosis. Atherosclerosis 1996;127(2):147-154.

39. Grundtman C, Kreutmayer SB, Almanzar G, Wick MC, Wick G. Heat shock protein 60 and immune inflammatory response in atherosclerosis. Arterioscler Thromb Vasc 2011;31(5):960-968.

40. Tabeta K, Yamazaki K, Hotokezaka H, Yoshie S, Hara K. Elevated humoral immune response to heat shock protein 60 (HSP60) family in periodontal patients. Clin Exp Immunol 2000;120(2):285-293.

41. Figuero E, Sánchez-Beltrán M, Cuesta-Frechoso S, Tejerina JM, del Castro JA, Gutiérrez JM, et al. Detection of periodontal bacteria in atheromatous plaque by nested polymerase chain reaction. J Periodontol 2011;82(10):1469-1477.

42. Hosomi N, Aoki S, Matsuo K, Deguchi K, Masugata H, Murao $\mathrm{K}$, et al. Association of serum anti-periodontal pathogen antibody with ischemic stroke. Cerebrovasc Dis 2012;34(5-6): 385-392.

43. Pussinen PJ, Alfthan G, Rissanen H, Reunasen A, Asikainen S, Knekt P. Antibodies to periodontal pathogens and stroke risk. Stroke 2004;35(9):2020-2023.

44. Enersen M, Nakano K, Amano A. Porphyromonas gingivalis fimbriae. J Oral Microbiol 2013;5:1-10.

45. Deanfield JE, Halcox JP, Rabelink TJ. Endothelial function and dysfunction: testing and clinical relevance. Circulation 2007;115(10):1285-1295.

46. Epstein SE, Zhou YF, Zhu J. Infection and atherosclerosis: emerging mechanistic paradigms. Circulation 1999;100(4): e20-e28.

47. Higashi Y, Goto C, Jitsuiki D, Umemura T, Nishioka K, Hidaka $\mathrm{T}$, et al. Periodontal infection is associated with endothelial dysfunction in healthy subjects and hypertensive patients. Hypertension 2008;51(2):446-453.

48. Amar S, Gokce N, Morgan S, Loukideli M, Van Dyke TE, Vita JA. Periodontal disease is associated with brachial artery endothelial dysfunction and systemic inflammation. Arterioscler Thromb Vasc Biol 2003;23(7):1245-1249.

49. Tonetti MS, D'Aiuto F, Nibali L, Donald A, Storry C, Parkar $\mathrm{M}$, et al. Treatment of periodontitis and endothelial function. N Engl J Med 2007;356(9):911-920.

50. Paraskevas S, Huizinga JD, Loos BG. A systematic review and meta-analyses on C-reactive protein in relation to periodontitis. J Clin Periodontol 2008;35(4):277-290.

51. Serrano C, Pérez C, Sabogal D. Effect of periodontal therapy on metabolic control and an inflammatory mediator in type 2 diabetic subjects: a report on 17 consecutive cases. J Int Acad Periodontol 2012;14(2):26-34.

52. Vidal F, Figueredo CM, Cordovil I, Fischer RG. Periodontal therapy reduces plasma levels of interleukin-6, C-reactive protein, and fibrinogen in patients with severe periodontitis and refractory arterial hypertension. J Periodontol 2009;80(5): 786-791.

53. Goutoudi P, Diza E, Arvanitidou M. Effect of periodontal therapy on crevicular fluid interleukin-6 and interleukin-8 levels in chronic periodontitis. Int J Dent 2012;2012:362905.

54. Konopka L, Pietrzak A, Brzezińska-Błaszczyk E. Effect of scaling and root planing on interleukin-1, interleukin-8 and MMP-8 levels in gingival crevicular fluid from chronic periodontitis patients. J Periodontal Res 2012;47(6):681-688.

55. Sun WL, Chen LL, Zhang SZ, Ren YZ, Qin GM. Changes of adiponectin and inflammatory cytokines after periodontal intervention in type 2 diabetes patients with periodontitis. Arch Oral Biol 2010;55(12):970-974.

56. Desvarieux M, Demmer RT, Jacobs DR, Papapanou PN, Sacco RL, Rundek T. Changes in clinical and microbiological periodontal profiles relate to progression of carotid intima-media thickness: the oral infections and vascular disease epidemiology study. J Am Heart Assoc 2013;2(6):e000254.

57. Lee YL, Hu HY, Huang N, Hwang DK, Chou P, Chu D. Dental prophylaxis and periodontal treatment are protective factors to ischemic stroke. Stroke 2013 Apr;44(4):1026-1030.

58. D'Aiuto F, Orlandi M, Gunsolley JC. Evidence that periodontal treatment improves biomarkers and CVD outcomes. J Clin Periodontol 2013;40(Suppl 14):S85-105.

59. Korhonen S, Saxlin T, Suominen L, Jula A, Knuuttila M, Ylöstalo P. Serum cholesterol ratios and periodontal infection: results of the Health 2000 Survey. J Clin Periodontol 2011;38(9): 787-794.

60. Saxlin T, Suominen-Taipale L, Kattainen A, Marniemi J, Knuuttila M, Ylöstalo P. Association between serum lipid levels and periodontal infection. J Clin Periodontol 2008; 35(12):1040-1047.

61. Fentoğlu O, Sözen T, Oz SG, Kale B, Sönmez Y, Tonguç MO, et al. Short-term effects of periodontal therapy as an adjunct to anti-lipemic treatment. Oral Dis 2010;16(7):648-654.

62. D'Aiuto F, Orlandi M, Gunsolley JC. Evidence that periodontal treatment improves biomarkers and CVD outcomes. J Periodontol 2013;84(Suppl 4):S85-S105.

63. Saini R, Saini S, Saini SR. Periodontal diseases: a risk factor to cardiovascular disease. Ann Card Anaesth 2010;13(2): 159-161. 